\title{
Ethnoveterinary medicinal plants: Preparation and application methods by traditional healers in selected districts of southern Ethiopia
}

\author{
Gebremedhin Romha Eshetu1 ${ }^{1}$, Tewedros Ayalew Dejene ${ }^{2}$, Lidet Befkadu Telila ${ }^{3}$ and Daniel Fekadu Bekele ${ }^{4}$
}

1. Department of Animal and Range Science, College of Agriculture and Natural Resource, Dilla University, P.O. Box 419, Dilla, Ethiopia; 2. Department of Plant Science, College of Agriculture and Natural Resource, Dilla University, P.O. Box 419, Dilla, Ethiopia; 3. Department of Horticulture, College of Agriculture and Natural Resource, Dilla University, P.O. Box 419, Dilla, Ethiopia; 4. Institute of Indigenous Studies, Dilla University, P.O. Box 419, Dilla, Ethiopia. Corresponding author: Gebremedhin Romha Eshetu, e-mail: gebremedhinromha@yahoo.com, TAD: teddy1360@yahoo.com, LBT: lidetbefikadutelila@yahoo.com, DFB: danielfekadu9@gmail.com Received: 09-11-2014, Revised: 14-04-2015, Accepted: 22-04-2015, Published online: 29-05-2015

doi: 10.14202/vetworld.2015.674-684 How to cite this article: Romha G, Dejene TA, Telila LB, Bekele DF (2015) Ethnoveterinary medicinal plants: Preparation and application methods by traditional healers in selected districts of southern Ethiopia, Veterinary World 8(5):674-684.

\begin{abstract}
Aim: The aim was to document the ethnoveterinary medicinal plants, their preparation, and application methods used by traditional healers in treating different animal diseases, in four districts with different culture and languages in southern Ethiopia.

Materials and Methods: Information of ethnoveterinary medicinal plants was obtained through in-depth direct interview with the local healers and field observations. A descriptive statistics was used to analyze the reported ethnoveterinary medicinal plants and associated indigenous knowledge. The informant consensus factor (ICF) was calculated for each category of diseases to identify the agreements of the informants on the reported cures. Preference ranking was used to assess the degree of effectiveness of certain medicinal plants against most prevalent animal diseases in the area.

Results: The healers had a very high intention to keep their traditional knowledge secrete and none of them was ready to transfer their knowledge either freely or on incentive bases to other people; they need to convey their knowledge only to their selected scions after getting very old. A total of 49 plant species used to treat 26 animal ailments were botanically classified and distributed into 34 families. The most commonly used plant parts for remedy preparations were leaves (38.8\%), followed by whole roots (20.4\%). Calpurnia aurea (Ait.) Benth was the most preferred effective treatment against external parasite and skin problem, which is the most prevalent disease with the highest ICF (0.68).

Conclusion: The study suggests that the community of the study districts depend largely on ethnoveterinary medicinal plants for the treatment of different animal ailments though the healers have a very high intention to keep their traditional knowledge secrete. Commonly reported plant species need to be tested for their antimicrobial activities in vitro and validated their active ingredients in order to recommend effective preparations and treatments to this community.
\end{abstract}

Keywords: animal ailments, ethnoveterinary medicinal plants, indigenous knowledge, traditional healers.

\section{Introduction}

Enthnoveterinary medicine is a holistic interdisciplinary study of the local knowledge and the socio-cultural structures and environment associated with animal health care and husbandry [1]. Hence, to keep animals healthy, traditional healing practices have been applied for centuries and have been passed down orally from generation to generation $[2,3]$. Widespread interest in documenting and validating ethnoveterinary practices arose in the early 1980s. Since then, several studies have been carried out, many reports written, and numerous conferences and workshops held. These activities have saved ethnoveterinary knowledge from extinction because most knowledge resided with elderly community members and disappeared as they died $[2,3]$. However, the effort is still quite insignificant when

Copyright: The authors. This article is an open access article licensed under the terms of the Creative Commons Attributin License (http:// creative commons.org/licenses/by/2.0) which permits unrestricted use, distribution and reproduction in any medium, provided the work is properly cited. compared to the undocumented global ethnoveterinary plant lore.

In Ethiopia, animal disease remains one of the principal causes of poor livestock performance, leading to an ever increasing gap between the supply of, and the demand for livestock products [4]. Conventional veterinary services, despite its paramount role, have limited coverage in developing countries [5,6]. Due to this reason livestock keepers particularly in rural areas frequently visit traditional healers to get solutions for their ill-health animals; they complement modern medicine by developing a socially acceptable remedy from inexpensive resources.

The traditional knowledge on ethnoveterinary practices by local healers who are knowledgeable and experienced in traditional systems of treatment is important, but their knowledge are not documented and is dwindling fast [7]. It is also indicated that the knowledge of ethnomedicinal plants is on the verge of irreversible loss and declining to deterioration due to the oral passage of herbal heritage from generation to generation rather than in writings, despite their vital 
role in catering for the health of human, and livestock population [8]. Environmental degradation, agricultural expansions, cultivation of marginal lands, and urbanization are also posing a significant threat to the future wellbeing of human and animal populations that have relied on these resources to combat various ailments for generations [9-11] warranting urgent need to document and preserve the indigenous knowledge. Hence, it is a timely endeavor to document, promote and conserve the country's ethnoveterinary medicinal plant lore. Such documents are important to define and maintain cultural identity of the people [12] in addition to serving as keys toward establishing people-centered natural resource management systems [13], and potentials for scientific discovery of new compounds used in the development of modern drugs [14].

Although attempts have been made to document Ethiopian ethnoveterinary medicinal plants in some cultural groups $[8,15-20]$, it is found insignificant when compared to the multi-ethnolinguistic communities found in the country, which have remained largely unexplored. Therefore, the present study was designed to document the ethnoveterinary medicinal plants, and their preparation and application methods used by traditional healers in treating different animal diseases, in the four districts with different culture and languages; Yabelo and Liben districts in Oromia region, and Wondo Genet and Kochere districts in southern nations region, southern Ethiopia.

\section{Materials and Methods}

\section{Ethical approval}

This study was approved by the Research and Dissemination Committee of Dilla University. The confidentiality of traditional property owners was completely maintained during processing our data. In addition, all data from this study were not shared with third party out of researchers. Informed consent was also obtained from the participants to ensure their willingness.

\section{Description of the study areas}

This study was conducted from May 2013 to July 2014 in the southern Ethiopia; Yabelo and Liben districts in Oromia regional state, Wondo Genet and Kochere districts in Southern Nations and Nationalities People Region (SNNPR) (Figure-1).

Liben and Yabelo districts are found in the Guji and Borena zonal administrative divisions of the Oromia Regional State. The people in the rural areas of both districts are pastoralists who make their livelihoods largely from livestock. They tend mixed herds of cattle, small ruminants, donkeys, and camels through seasonal movements between the wet and dry seasons grazing areas. Most of the areas in these districts are classified as lowlands, with ponds and wells serving as water sources for both people and livestock during the dry months [21]. The livestock population in Yabelo district is $1,496,652$ cattle, 625,198 small ruminants,

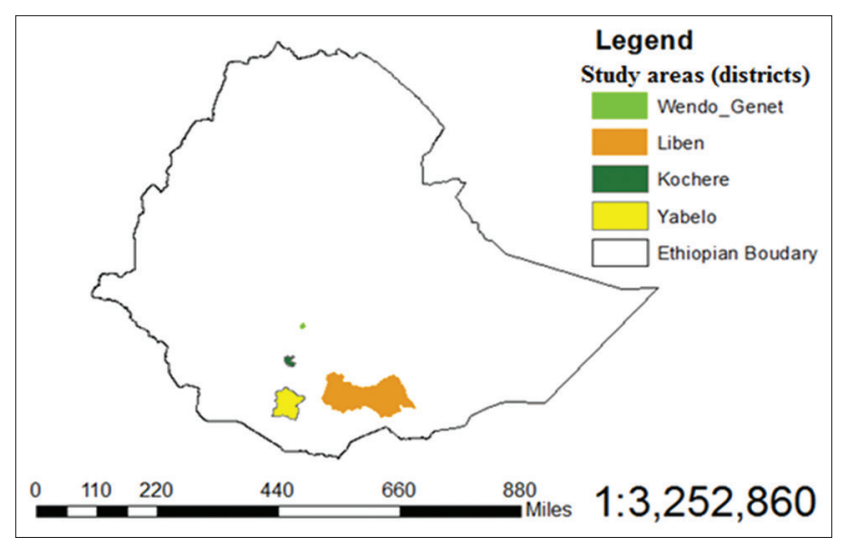

Figure-1: Location of the study districts.

75,644 equines, and 106,366 camels. Similarly, the livestock population in Liben district is $1,619,911$ cattle, 1,003,027 small ruminants, 192,784 equines, and 235,105 camels (Borena and Guji zones pastoral development office, unpublished data).

The climatic condition in both districts is semiarid with highly variable rainfall between 300 and 900 millimeters $(\mathrm{mm})$ a year, with high spatial and temporal variability. Liben district is located $569 \mathrm{~km}$ south of the capital city of Ethiopia, Addis Ababa at about $310 \mathrm{~km}$ southeast of Hawassa. The altitude range of the area is between $1,000 \mathrm{~m}$ and $2,000 \mathrm{~m}$ above sea level (a.s.1.) with the coordinates $4^{\circ} 40^{\prime}-5^{\circ} 20^{\prime} \mathrm{N}$ and $39^{\circ} 10^{\prime}-3^{\circ} 30^{\prime} \mathrm{E}$. Moreover, the town of Yabello is geographically found at $5^{\circ} 23^{\prime} 49^{\prime \prime} \mathrm{N} 39^{\circ} 33^{\prime} 52^{\prime \prime} \mathrm{E}$, and located at a distance of $565 \mathrm{~km}$ Southern of Addis Ababa with an altitude 1000-1650 m a.s.l.

Wondo Genet, is found in Sidama Zone, SNNPR State, located on the western escarpment of the central rift valley of Ethiopia, that extend between $7^{\circ} 06^{\prime} \mathrm{N}$ and $38^{\circ} 37^{\prime} \mathrm{E}, 1720-2620 \mathrm{~m}$ a.s.1., about $272 \mathrm{~km}$ south of the capital city, Addis Ababa and about $24 \mathrm{~km}$ east of Hawassa Town. The Farming system practicing in the district is crop-livestock mixed farming. The dominant livestock being reared in the district is cattle $(31,156)$, small ruminants $(13,380)$, and equines $(2,749)$. The climatic condition is humid and sub-humid with average annual temperatures of between $14^{\circ} \mathrm{C}$ and $20^{\circ} \mathrm{C}$ and annual rainfall between $700 \mathrm{~mm}$ and $1100 \mathrm{~mm}$ (Wondo Genet Agricultural and Rural Development Office, unpublished data).

Kochere district is geographically situated at $05^{\circ} 55^{\prime}-06^{\circ} 07^{\prime} \mathrm{N}$ and $038^{\circ} 15^{\prime}-038^{\circ} 5^{\prime} \mathrm{E}$. It is at a distance of $420 \mathrm{~km}$ south of the capital city, Addis Ababa; $150 \mathrm{~km}$ south of the regional town Hawassa and $67 \mathrm{~km}$ east of the zonal town Dilla with an altitude ranging from 1500 to $3700 \mathrm{~m}$ a.s.l. The climatic condition of the district is humid with an average annual temperature and rainfall, $13-24^{\circ} \mathrm{C}$ and, $760-1500 \mathrm{~mm}$, respectively. Crop-livestock mixed farming system is being practiced in Kochere district and the dominant livestock raised in the district is cattle $(12,663)$, small ruminants $(20,308)$, and equines $(3,625)$ (data collection and dissemination work process of Gedeo Zone, unpublished data). 


\section{Study design and selection of participants}

A cross-sectional study was conducted using semi-structured questionnaires to gather information on the traditional usage of plants in the health care system of animals. The study districts were purposefully selected as these communities highly rely on traditional healings and possess many skills acquired from fore parents. Selection of informants was performed as in the manner described by Martin [22] who stated that when recording indigenous knowledge controlled by ethnobotanical healers or by certain social groups, the choice of key informant is vital. Thirty-one traditional healers (27 males and 4 females) were selected purposively based on the recommendation from local elders and governmental bodies; 13 from Liben and Yabelo districts (Oromia region), 13 from Wondo Genet district (Sidama zone), and 5 from Kochere districts (Gedeo zone) of southern nations region. The selected healers were well-known in the community due to their long practice in providing services related to traditional veterinary medicinal plants. The ages of the healers were between 35 and 91 years. During data collection, preliminary discussion was held with the individual key informants through assistance of the local elders and governmental bodies to elaborate the objective of the study.

\section{Plant specimen collections and identifications}

Information of medicinal plants was obtained through a direct interview with the local healers and field observations. In-depth interview was also done to address details on the types and characteristics of plant and their traditional preparation, parts used, route of administration, dose given by the local healers, duration of the treatment, and other plants used together. Moreover, information was collected about the way of passing the indigenous knowledge from generation to generation. Voucher specimens were collected, coded by their vernacular names, pressed, and dried for identification. The plants identification was performed both in Dilla University in the department of biology by botany specialists $[23,24]$, and at the National Herbarium of Addis Ababa University. All voucher specimens of the ethnoveterinary medicinal plants were labeled with scientific and vernacular names and stored in mini-herbarium in the College of Agriculture and Natural Resources, Dilla University.

\section{Quality assurance}

To maintain the quality of data during interview, each informant was contacted at least 2 times for the same ideas and the validity of the information was proved and recorded. In case, the idea of the informant deviated from the original information, it was rejected as it was regarded irrelevant information. Only the relevant data were taken into account and statistically analyzed. Furthermore, the data quality was ensured through training of data collectors, checking of missing data, data cleaning, and careful data analysis.

\section{Data analysis}

A descriptive statistical methods, percentage, and frequency were used to analyze the reported ethnoveterinary medicinal plants' data and associated indigenous knowledge. The informant consensus factor (ICF) was computed for each category of diseases to identify the agreements of the informants on the reported cures for the group of diseases. The ICF was calculated as follows: Number of use citations in each category (nur) minus the number of species used (nt), and divided by the numbers of use citations in each category minus one [25].

$$
\mathrm{ICF}=\frac{\text { nur }-\mathrm{nt}}{\text { nur }-1}
$$

Preference ranking was computed to assess the degree of effectiveness of certain medicinal plants against most prevalent diseases in the area. The medicinal plant that was believed to be the most effective was given the highest value, i.e., 5, and the one with the least effectiveness received the lowest value, i.e., 1 [22].

\section{Results}

\section{Knowledge and practice toward ethnoveterinary} medicinal plants

Of the 31 traditional healers interviewed, $29(93.5 \%)$ reported that they acquired their knowledge from their parents or close relatives while $2(6.5 \%)$ of the traditional healers responded that they acquired the medicinal plant knowledge on payment. The healers had a very high intention to keep their traditional knowledge secrete and none of them was ready to transfer their knowledge either freely or on incentive bases to other people. They need to convey their knowledge only to their selected scions (one herbalist can transfer his/her knowledge only to one of his/her selected son or daughter) after getting very old. According to the traditional healers, the medicine does not work if it is being told freely and sold to others.

\section{Diversity of ethnoveterinary medicinal plants}

A total of 63 different ethnoveterinary medicinal plants used by various farmers of the study areas to treat a wide range of animal disease situations were collected and submitted to the National Herbarium of Addis Ababa University for botanical classification. Of these, 49 plant species having ethnoveterinary medicinal value were botanically classified and grouped under 34 families. About $24 \%$ of the botanical families were represented by more than one species. In this study, the highest number of plant species having ethnoveterinary medicinal value were found in Euphorbiaceae, Fabaceae and Solanaceae, with 4 plant species each followed by Amaryllidaceae (3 species). Four of the reported botanical families, i.e., Asteraceae, Cucurbitaceae, Meliaceae and 
Myrtaceae were represented by 2 species each. The remaining $26(76 \%)$ families had a single species representation. A summary of the local and botanical names of the reported ethnoveterinary medicinal plants, and their indications, parts used, dose used by the local healers, preparations, and routes of administrations is presented in Table-1. Herbs were the most harvested for ethnoveterinary medicinal purpose and were represented with $18(36.7 \%)$ plant species followed by $17(34.7 \%)$ trees. Shrubs and climbers representing 7 (14.3\%) plant species each (Table-2).

\section{Methods and form of remedy preparation, dosages, and routes of administration}

About $63.3 \%$ ethnoveterinary medications were reported to comprise remedial parts of a single medicinal plant while $36.7 \%$ were prepared using formulations from two or more medicinal plant species either similar or different parts of the plants. Freshly harvested plant parts were the dominant ones $(85.7 \%)$ used in remedy preparation whereas the remaining $14.3 \%$ of remedies were reported to be prepared from dried parts of medicinal plant species. The most commonly used plant parts for remedy preparations were leaves $(38.8 \%)$, followed by whole roots $(20.4 \%)$ (Figure-2).

Various methods of ethnoveterinary medicinal plants preparations were documented in this study based on type and form of animal ailments being treated. Pounding the remedial part and mixing it with water at room temperature was found to be the major method of remedy preparation $(78.2 \%)$, followed by crushing and squeezing or chewing the remedial part of the ethnoveterinary medicinal plant without the use of water $(12.7 \%)$. The remaining remedial methods preparations were collection of latex from the plants with or without the use of water $(7.3 \%)$, and tie or put on $(1.8 \%)$ the plant (climber) as it is on the neck of the animal. The most frequently used forms of preparation was liquid form $(90.9 \%)$ and administered through mouth, nose, and eye, and applied topically followed by paste and latex (7.3\%) and tie or put on $(1.8 \%)$. However, two or more methods of remedy preparations and formulations were observed from a single plant depending on the type of disease to be treated (Table-1).

During preparation and dosage estimation of the local medicines, healers used various units of measurements; numbers (e.g., for seeds, fruits, bulbs, and flowers), spoon (e.g., for paste and powdered plant parts), and cups (e.g., for water during preparation and liquid form of the prepared medicine). However, no strictly standardized doses of herbal preparations as known for modern veterinary medicine were reported by traditional healers for any of the preparations used to treat livestock ailments in the present study. The dosage regime is generally dependent on the age and species of the animal. A single plant was found to be administered in different routes depending up on the preparation and type of the disease needed to be treated. Oral administration was found to be as the most frequently (63.3\%) utilized route of administration followed by topical application (16.7\%) (Table-3).

\section{Animal ailments and preference of ethnoveterinary medicinal plants}

A total of 26 animal ailments were found in the area to be treated by a variety of medicinal plants (Table-1). The category: External parasite and skin problem have the highest ICF (0.68) followed by diarrhea and dysentery with 0.65 ICF (Table-4). Preference ranking of five medicinal plants that were reported as an effective treatment for external parasite and skin problem, which is the most common disease in the study area was conducted after selecting 6 key informants. Calpurnia aurea (Ait.) Benth was the most preferred effective treatment against the external parasite and skin problem followed by Commiphora erythraea in the study districts (Table-5). Three plants namely, C. aurea (Ait.) Benth, Croton macrostachyus, and Nicotiana tabacum L. were reported as treatment of external parasite and skin problem in all the study areas having different cultures and languages.

\section{Discussion}

In the present study, $93.5 \%$ of traditional healers responded that they acquired their knowledge from

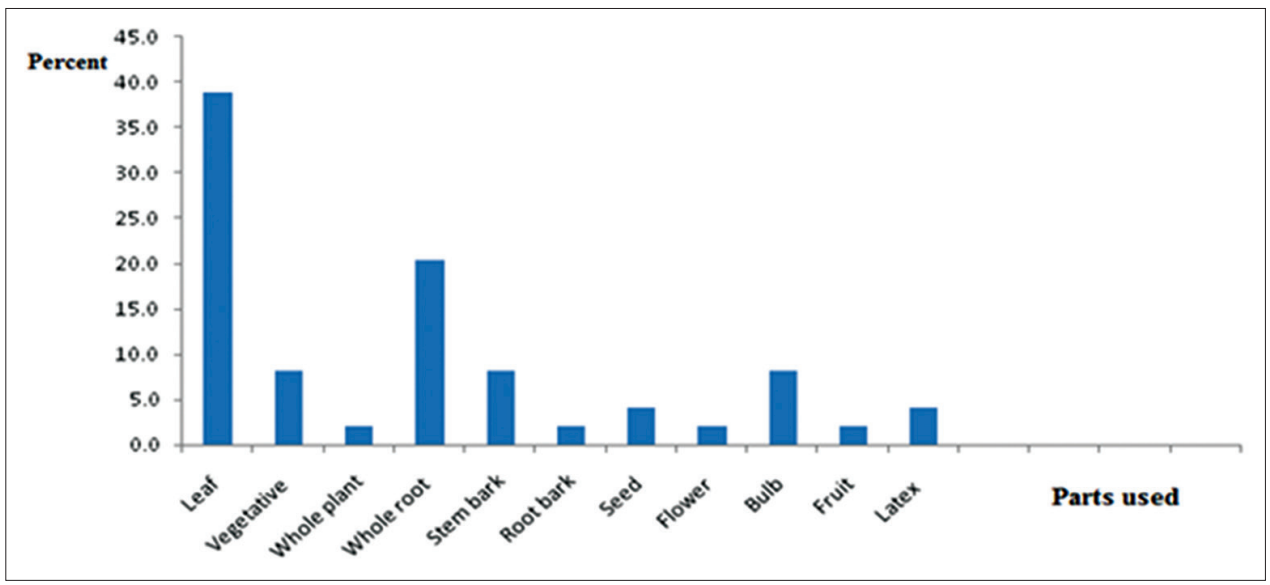

Figure-2: Plant parts used by the traditional healers for remedy preparation in the study areas. 


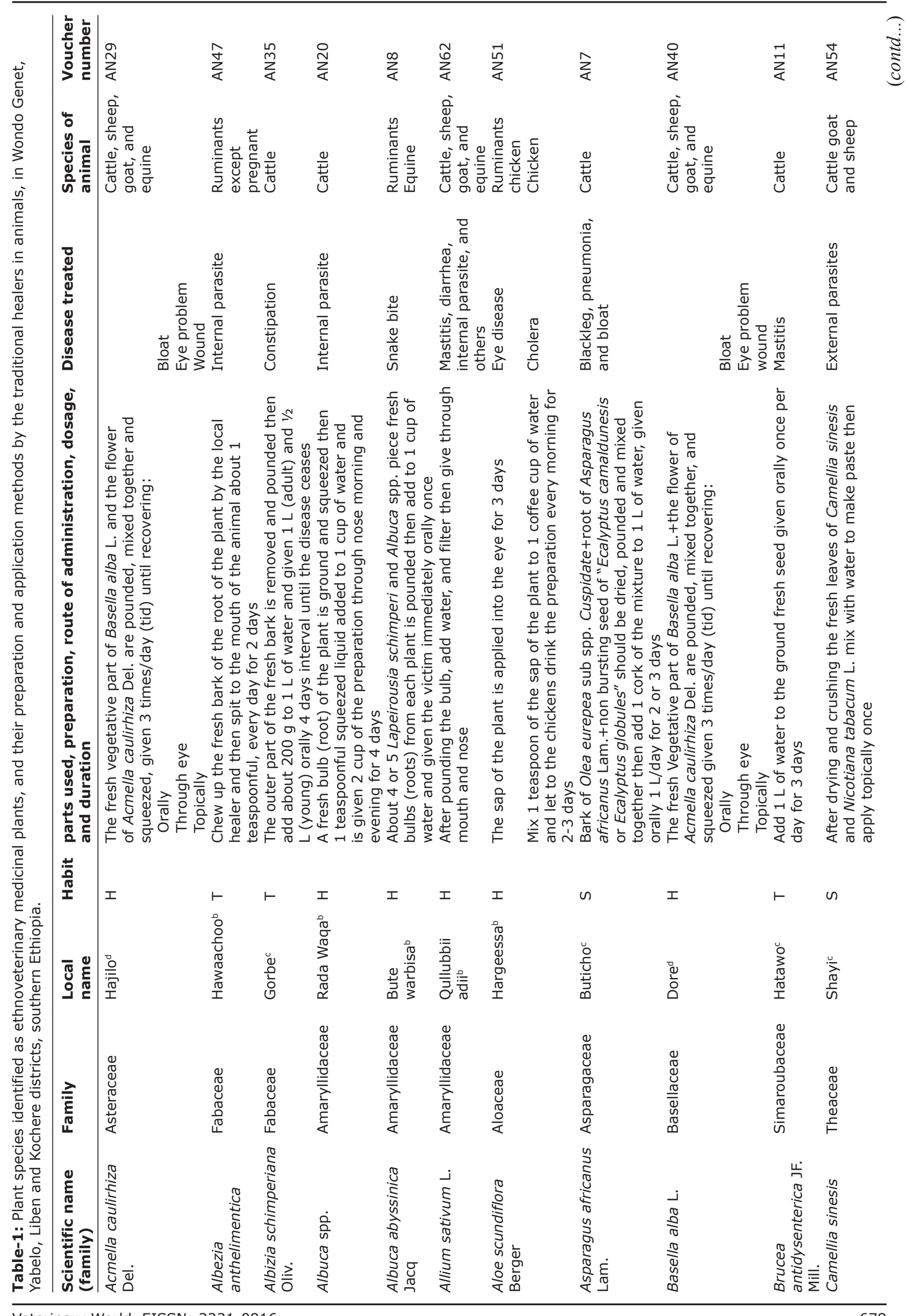




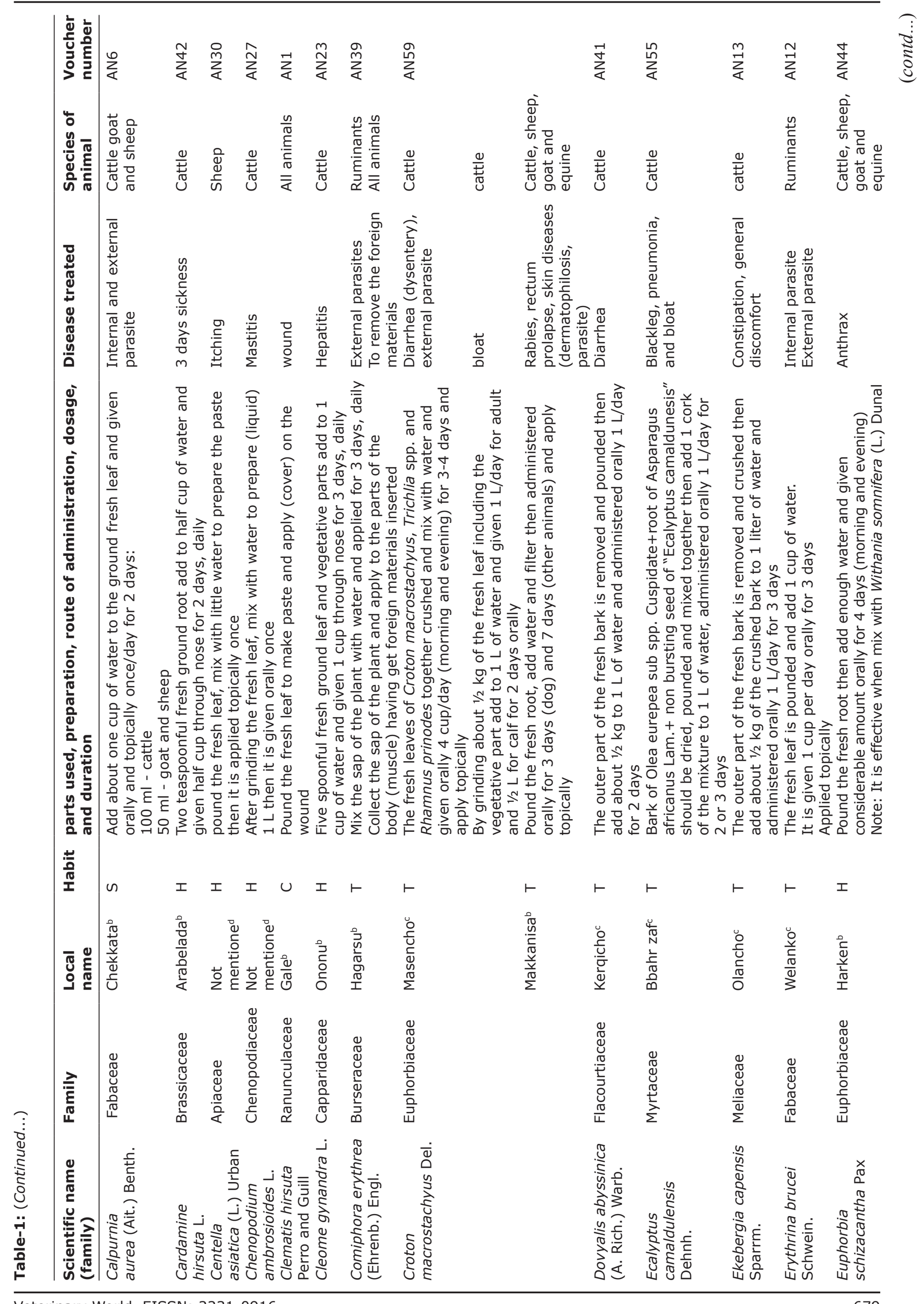




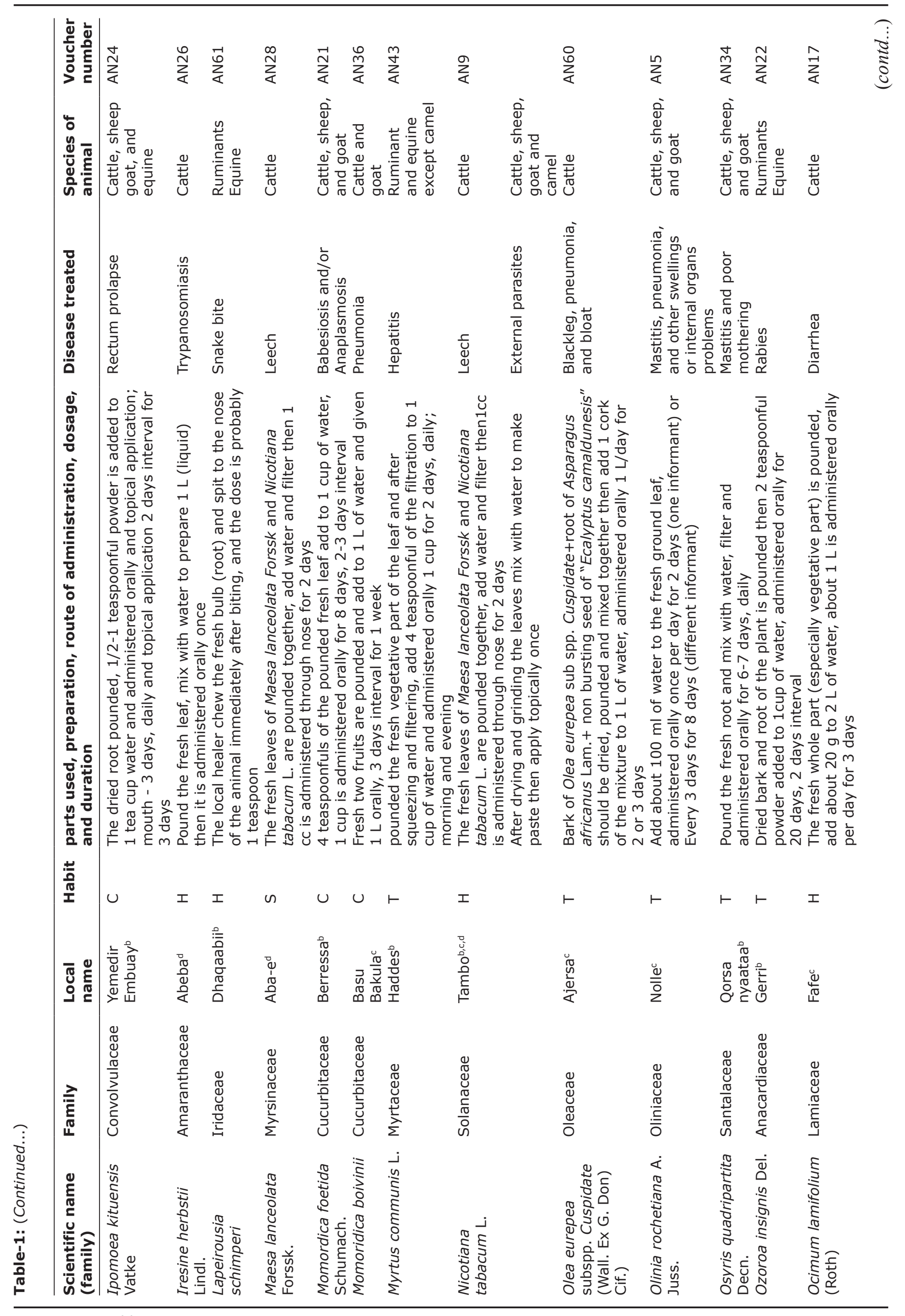




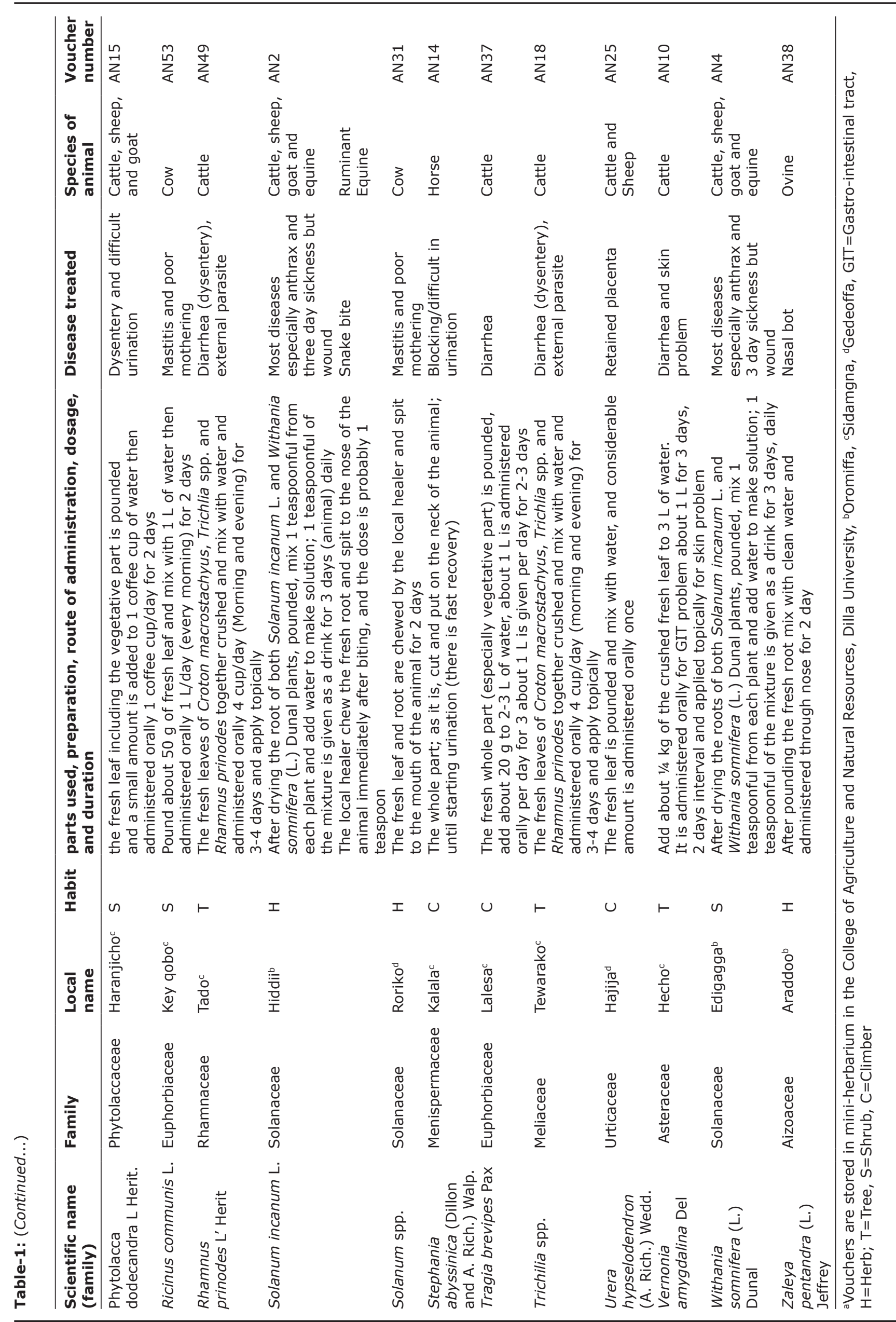


Table-2: Growth habit of ethnoveterinary medicinal plants identified in the study area.

\begin{tabular}{lcc}
\hline Habit & Frequency of response & Proportion (\%) \\
\hline Herb & 18 & 36.7 \\
Tree & 17 & 34.7 \\
Shrub & 7 & 14.3 \\
Climber & 7 & 14.3 \\
Total & 49 & 100 \\
\hline
\end{tabular}

Table-3: Routes of administration of the ethnoveterinary medicinal plants identified in the study area.

\begin{tabular}{lcc}
\hline $\begin{array}{l}\text { Route of } \\
\text { administration }\end{array}$ & $\begin{array}{c}\text { Frequency } \\
\text { of response }\end{array}$ & $\begin{array}{c}\text { Proportion } \\
\mathbf{( \% )}\end{array}$ \\
\hline Oral & 38 & 63.3 \\
Topical & 10 & 16.7 \\
Nasal & 8 & 13.3 \\
Ocular & 3 & 5.0 \\
Tie on & 1 & 1.7 \\
Total & 60 & 100 \\
\hline
\end{tabular}

Table-4: Informant consensus factor by categories of diseases in the study districts.

\begin{tabular}{lccc}
\hline Category of disease & $\begin{array}{c}\text { Number } \\
\text { of plant } \\
\text { species }\end{array}$ & $\begin{array}{c}\text { Number of } \\
\text { informant } \\
\text { cited }\end{array}$ & ICF \\
\hline External parasite and skin & 10 & 29 & 0.68 \\
problem & 9 & 24 & 0.65 \\
Diarrhea and dysentery & 8 & 20 & 0.63 \\
Internal parasite, nasal bot & & & \\
and leech & 4 & 9 & 0.63 \\
Snake poisoning & 8 & 18 & 0.59 \\
Bloat and constipation & 7 & 15 & 0.57 \\
Mastitis and poor mothering & 4 & 7 & 0.50 \\
Pneumonia & 3 & 5 & 0.50 \\
Eye problem & 8 & 14 & 0.46 \\
Anthrax, black leg and & & & \\
3-day sickness & 14 & 19 & 0.28 \\
Others & & &
\end{tabular}

ICF=Informant consensus factor

Table-5: Preference ranking of ethnoveterinary medicinal plants used for treating external parasite and skin problem in the study districts.

\begin{tabular}{lccccccccc}
\hline List of medicinal plants & $\mathbf{R}_{\mathbf{1}}$ & $\mathbf{R}_{\mathbf{2}}$ & $\mathbf{R}_{\mathbf{3}}$ & $\mathbf{R}_{\mathbf{4}}$ & $\mathbf{R}_{\mathbf{5}}$ & $\mathbf{R}_{\mathbf{6}}$ & Total & $\mathbf{R a n k}$ \\
\hline Commiphora erythraea & 5 & 4 & 3 & 3 & 3 & 5 & 23 & $2^{\text {nd }}$ \\
Calpurnia aurea (Ait.) & 5 & 4 & 4 & 5 & 3 & 5 & 26 & $1^{\text {st }}$ \\
Benth & & & & & & & & \\
Croton macrostachyus Del & 3 & 4 & 2 & 4 & 3 & 1 & 17 & $3^{\text {rd }}$ \\
Nicotiana tabacum L. & 3 & 3 & 4 & 2 & 2 & 1 & 15 & $4^{\text {th }}$ \\
Erythrina brucei Schwein. & 1 & 2 & 1 & 2 & 3 & 2 & 11 & $5^{\text {th }}$ \\
\hline
\end{tabular}

$\mathrm{R}=$ Represented respondents

their parents or close relatives. Moreover, the local healers have a very high intention to keep their ethnoveterinary knowledge secrete and none of them was ready to transfer their knowledge either freely or on incentive bases to other people. In line with the present study, other studies have reported that the highest medicinal plant knowledge acquisition by the healers was from parents or close relatives and they have a very high intention to keep their traditional knowledge secrete $[8,19]$.
Forty-nine plant specimens having ethnoveterinary medicinal value were botanically classified and distributed into 34 families. In this study, the highest number of plant species having ethnoveterinary medicinal value were found in Euphorbiaceae, Fabaceae and Solanaceae, with 4 plant species each and Amaryllidaceae (3 species). In agreement with this study, Asteraceae, Cucurbitaceae, Euphorbiaceae, Fabaceae, and Solanaceae have also been reported as dominant families in other studies [18-20]. Moreover, consistent with this study Mesfin et al. [8] have reported that herbs were the most harvested for the ethnoveterinary medicinal purpose. However, discordant to this study shrubs have been documented as the most important ethnoveterinary medicinal plants in the other part of the country [20].

The most commonly used plant parts for remedy preparations were leaves $(38.8 \%)$, followed by whole roots $(20.4 \%)$. Consistent with this study, leaf has been identified as the most frequently used plant part $[18,19]$; however, in contrast to this study, Lulekal et al. [20] have found that root is as the most used part in their studies. This difference could be as the pharmaceutical value and concentration of active ingredients in each plant varied depending on climatic and edaphic factors. People inhabiting different ecological zones use different plants and plant parts in their treatment arsenal [15].

Results also indicate pronounced preference of traditional healers in the study districts to make use of freshly harvested plant parts $(85.7 \%)$ for remedy preparation over dried forms. Similar observations were reported $[10,16,20]$ for other cultural groups living in Ethiopia. This could be attributed to the widespread traditional belief of attaining high efficacy from fresh remedies due to higher presence of active ingredients in the form of secondary metabolites in cases of fresh plant parts which community members rightly thought could be lost on drying.

About $63.3 \%$ ethnoveterinary medications were reported to comprise remedial parts of a single medicinal plant in the present study which is in agreement with the findings of studies conducted elsewhere in Ethiopia [26] and Pakistan [27]. However, 36.7\% of the traditional medications were also prepared using formulations from two or more ethnoveterinary medicinal plant species either similar or different parts of the plants for treating livestock ailments may be attributed to the expected synergetic effect of combinations of parts and their bioactive ingredients to treat ailments. Giday et al. [28] have also reported the therapeutic efficacy of combinations of medicinal plant parts used in other peoples living in northwest Ethiopia for treating various ailments.

Pounding the remedial part and mixing it with water at room temperature was found to be the most common method of local drugs extraction (78.2\%), which is in line as documented in other studies $[19,28]$. Oral $(63.3 \%)$ route of administration is popular as in 
the finding of Tamiru et al., [19] who reported oral as the leading route of administration used in western Ethiopia. It is also in agreement with the result of various ethnobotanical studies conducted elsewhere in Ethiopia $[8,15,20,29]$ which indicates oral as the predominant route of administration used by the herbalists. A single plant was found to be prepared in different formulations and administered in different routes depending up on the type of the disease needed to be treated as reported by Tamiru et al. [19].

Even though healers used various units of measurements to estimate doses of local medicines such as numbers (e.g., for seeds, fruits, bulbs, and flowers), spoon (e.g., for paste and powdered plant parts), and cups (e.g., for water during preparation and liquid form of the prepared medicine), no strictly standardized doses of herbal preparations as known for modern veterinary medicine were reported by traditional healers for any of the preparations used to treat livestock ailments in the present study areas. Similar findings have been reported in other studies $[17,20]$.

C. aurea (Ait.) Benth, Commiphora erythraea, Nicotiana tabacum L., Croton macrostachyus Del, and Erythrina brucei Schwein were the ethnoveterinary medicinal plants identified and were used to treat external parasite and skin problem which was the most prevalent animal health problem reported in the study area. C. aurea (Ait.) Benth, Nicotiana tabacum L. and Croton macrostachyus Del have been reported [17] as treatment of external parasite and skin problem in animals in Tigray region, northern Ethiopia. Gebrezgabiher et al. [18] also documented that $C$. aurea (Ait.) Benth is being frequently used as ethnoveterinary medicinal plants for treatment of external parasite and skin problem in animals in northern Ethiopia.

\section{Conclusion}

The study suggests that there is a vast amount of indigenous knowledge on ethnoveterinary medicinal plant and this knowledge plays an important role for the treatment of different animal ailments in the study districts. The healers have a very high intention to keep their traditional knowledge secrete and none of them was ready to transfer their knowledge either freely or on incentive bases to other people; they need to convey their knowledge only to their selected scions after getting very old. The knowledge is passed from generation to generation in an oral manner. Without being properly documented this information it could easily be lost or distorted. Commonly reported plant species need to be tested for their antimicrobial activities in vitro and validated their active ingredients in order to recommend effective preparations and treatments to this community.

\section{Authors' Contributions}

GRE has planned and designed the study. All authors conducted the field work. GRE has analyzed the data, supervised all stages of the work including during botanical identification of the plants and has written the draft of this report. All authors read and approved the final manuscript.

\section{Acknowledgments}

This research received financial support from Research and Dissemination office of Dilla University; grant number - AgNR/ARSc/2013/020. The funder had no role in study design, data collection and analysis, decision to publish, or preparation of the manuscript. The authors are thankful to Mrs. Tariku Berihun and Melaku Wondefrash for their help in identifying the plants botanically, and Mr. Birhane Gebrehiwot for the GIS work. We are also grateful to the local healers in the study areas who were willing to share their indispensable ethnoveterinary medicine knowledge.

\section{Competing Interests}

The authors declare that they have no competing interests.

\section{References}

1. Tiwari, L. and Pande, P.C. (2010) Enthnoveterinary medicine in Indian perspectives: Reference to Uttarakhand, Himalaya. Indian J. Tradit. Knowl. 9: 611-17.

2. Toyang, N.J., Mertens, H. and Otterloo-Butler. S. (2007) Ethnoveterinary Medicine: A Practical Approach to the Treatment of Cattle Diseases in Sub-Saharan Africa. $2^{\text {nd }}$ ed. Technical Centre for Agricultural and Rural Cooperation. Agromisa, Wageningen, Netherlands. p1-87.

3. Phondani, P.C., Maikhuri, R.K. and Kala, C.P. (2010) Ethnoveterinary uses of medicinal plants among traditional herbal Healers in Alaknanda catchment of Uttarakhand, India. Afr. J. Trade.Camplement, 7: 195-206.

4. Agrawal, A. (1995) Indigenous and scientific knowledge: Some critical comments. Indig. Knowl. Dev. Monit., 3: 3-35.

5. Girish, H.V. and Satish, S.(2008) Antibacterial activity of important medicinal plants on human pathogenic bacteria-a comparative analysis. World App. Sci. J., 5: 267-271.

6. Devi, K., Karthikai, G.D., Thirumaran, G., Arumugam, R. and Anantharaman, P. (2010) Antibacterial activity of selected medicinal plants from Parangipettai coastal regions; Southeast coast of India. Acad. J. Plant Sci., 3: 122-125.

7. Bekele, E. (2007) Actual Situation of Medicinal Plants in Ethiopia. Prepared for Japan Association for International Collaboration of Agriculture and Forestry (JAICAF). Available from: http://www.endashaw.com. [Accessed on 2014 Jul 30].

8. Mesfin, F., Demissew, S. and Teklehaymanot, T. (2009) An ethnobotanical study of medicinal plants in Wonago Woreda, SNNPR, Ethiopia. J. Ethnobiol. Ethnomed., 5: 28.

9. Teklehaymanot, T. and Giday, M. (2007) Ethno botanical study of medicinal plants used by people in Zegie peninsula, north western Ethiopia. J. EthnoBiol. Ethnomed., 3: 12.

10. Lulekal, E., Kelbessa, E., Bekele, T. and Yineger, H. (2008) An ethnobotanical study of medicinal plants in Mana Angetu District, southeastern Ethiopia. J. Ethnobiol. Ethnomed., 4: 1-10.

11. Giday, M., Asfaw, Z. and Woldu, Z. (2009) Medicinal plants of the Meinit ethnic group of Ethiopia: An ethnobotanical study. J. Ethnopharmacol., 124: 513-521.

12. Cetinkaya, G. (2009) Challenges for the maintenance of traditional knowledge in the Satoyama and Satoumi ecosystems, Noto peninsula, Japan. Hum. Ecol. Rev., 16: 27-40.

13. Lynam, T., De Jong, W., Sheil, D., Kusumanto, T. and Evans, K. (2007) A review of tools for incorporating community 
knowledge, preferences, and values into decision making in natural resources management. Ecol. Soc., 12: 5.

14. Cos, P., Vlietinck, A.J., Vanden Berghe, D. and Maes, L. (2006) Anti-infective potential of natural products: How to develop a stronger in vitro 'proof - of concept'. J. Ethnopharmacol., 106: 290-302.

15. Sori, T., Bekana, M., Adunga, G. and Kelbesa, E. (2004) Medicinal plants in ethnoveterinary practices of borana pastoralists, Southern Ethiopia. Int. J. Appl. Res. Vet. Med., 2: 220-225.

16. Yineger, H., Kelbessa, E., Bekele, T. and Lulekal, E. (2007) Ethnoveterinary medicinal plants at Bale mountains national park, Ethiopia. J. Ethnopharmacol., 112(1): 55-70.

17. Kalayou, S., Haileselassie, M., Gebre-egziabher, G., Tiku'e, T., Sahle, S., Taddele, H. and Ghezu, M. (2012) In-vitro antimicrobial activity screening of some ethnoveterinary medicinal plants traditionally used against mastitis, wound and gastrointestinal tract complication in Tigray Region, Ethiopia. Asian Pac. J. Trop. Biomed., 2(7): 512-522.

18. Gebrezgabiher, G., Kalayou, S. and Sahle, S. (2013) An ethnoveterinary survey of medicinal plants in woredas of Tigray region, Northern Ethiopia. Int. J. Biodivers. Conserv., 5: 89-97.

19. Tamiru, F., Terfa, W., Kebede, E., Dabessa, G., Roy, R.K. and Sorsa, M. (2013) Ethnoknowledge of plants used in veterinary practices in Dabo Hana District, West Ethiopia. J. Med. Plants Res., 7: 2960-2971.

20. Lulekal, E., Asfaw, Z., Kelbessa, E. and Damme, P.V. (2014) Ethnoveterinary plants of Ankober District, North Shewa Zone, Amhara Region, Ethiopia. J. Ethnobiol. Ethnomed., 4: 10.
21. Bekele, G. and Abera, T. (2008) Livelihoods-based drought response in Ethiopia: Impact assessment of livestock feed supplementation need. Available from: http://www.fic.tufts. edu/assets/IMPACT1-2.pdf. [Accessed on 2014 Jul 30].

22. Martin, G.J. (1995) Ethnobotany: A Methods Manual. WWF for Nature International, Chapman and Hall, London, UK. p265-270.

23. Edwards, S., Tadesse, M., Demissew, S. and Hedberg, I. (2000) Magnoliaceae to flacourtiaceae. In: Flora of Ethiopia and Eritrea Part 1. Vol. 2. The National Herbarium Addis Ababa, Ethiopia and Upssala, Sweden.

24. Hedberg, I., Kelbessa, E., Edwards, S., Demissew, S. and Persson, E. (2006) Plantaginaceae. In: Flora of Ethiopia and Eritrea. Vol. 5. The National Herbarium, Addis Ababa University, Ethiopia and Uppsala.

25. Heinrich, M., Ankl, A., Frei, B., Weimann, C. and Sticher, O. (1998) Medicinal plants in Mexico: Healer's consensus and cultural importance. Soc. Sci. Med., 47: 1863-1875.

26. Giday, M., Asfaw, Z. and Woldu, Z. (2010) Ethnomedicinal study of plants used by Sheko ethnic group of Ethiopia. J. Ethnopharmacol., 132: 75-85.

27. Hassan, H., Murad, W., Tariq, A. and Ahmad, A. (2014) Ethnoveterinary study of medicinal plants in Malakand Valley, District Dir (Lower), Khyber Pakhtunkhwa, Pakistan. Ir. Vet. J., 67: 6.

28. Giday, M., Teklehaymanot, T., Animut, A. and Mekonnen, Y. (2007) Medicinal plants of the Shinasha, Agew-awi and Amhara peoples in northwest Ethiopia. J. Ethnopharmacol., 110: 516-525.

29. Giday, M., Asfaw, Z., Woldu, Z. and Elmquist, T. (2003) An ethnobotanical study of medicinal plants by the Zay people in Ethiopia. J. Ethnopharmacol., 85: 43-52. 